\title{
IX \\ A COMPREENSÃO DOS PROFESSORES REFERENTE À PEDAGOGIA HISTÓRICO-CRÍTICA NO CURRÍCULO MUNICIPAL DE CASCAVEL*
}

Josiane de Kassia Marmentini

Paulino José Orso

\section{INTRODUÇÃO}

A Pedagogia Histórico-Crítica (PHC) representa um marco para a educação brasileira. Surgiu em 1979, tendo como precursor Dermeval Saviani. É uma proposta que pretende superar as teorias não críticas e críticoreprodutivistas. Em 1990, o governo do Paraná a assume como fundamentação teórica do Currículo Básico para a Escola Pública do Paraná (CBEPPR).

Se analisarmos o documento, verifica-se que não se trata de uma proposta baseada integralmente nesta teoria, visto que incorporou elementos da PHC e também de outras teorias pedagógicas, ou seja, há um certo ecletismo. Com isso, na prática deixou a desejar, em parte devido às descontinuidades políticas e, em parte, pela ausência de compromisso de parte dos docentes.

Diferente da implantação do Currículo no Estado do Paraná, Cascavel, que teve como intuito reorganizar o processo educativo de forma coletiva, a rede planejou e construiu uma proposta que atendesse as especificidades e demandas do Município. Foram muitos estudos, discussões e reflexões para chegar aos pressupostos filosóficos, psicológicos e pedagógicos. Contudo, foi pensado, planejado e sistematizado pelos próprios professores da rede que, naquele momento, pretendiam elaborar uma proposta em consonância com a concepção de homem, sociedade e educação emancipadora, comprometida com a defesa da escola pública, laica, gratuita e de qualidade para a classe trabalhadora.

De acordo com Malanchen, Matos e Pagnoncelli (2016, p. 63):

*DOI - 10.29388/978-65-86678-77-2-0-f.124-134 
Apesar de todos os obstáculos e contradições, o Currículo foi elaborado e acredita-se que seus fundamentos trazem a possibilidade de construção da autonomia e das condições para a tomada de consciência da classe trabalhadora, tendo um enfoque principal no "o que ensinar", aproximando os alunos da riqueza intelectual produzida historicamente. Neste documento, busca-se esclarecer que a finalidade da escola deve determinar os métodos e processos de ensino-aprendizagem. Assim, a transmissão-apropriação do conhecimento sistematizado torna-se o foco da definição do saber escolar, portanto, o conhecimento deve ser o elemento central da referência para a organização do ensino.

O Currículo foi concluído em 2007 e implementado em 2008, fundamentado na Pedagogia Histórico-Crítica e na Psicologia Histórico Cultural, que adotam como método, o materialista histórico dialético. Constitui-se como um documento de organização curricular, que dispõe acerca das concepções de cada disciplina, os encaminhamentos metodológicos, os conteúdos e os critérios de avaliação.

Conforme preconiza o Currículo Municipal de Cascavel (CMC), a função da escola é garantir a socialização dos conteúdos científicos mais elaborados.

A escola deve assegurar aos alunos o contato com os conhecimentos científicos mais elaborados, pois são estes que efetivamente possibilitarão a autonomia e a tomada de consciência da classe trabalhadora, tendo um enfoque principal no "o que ensinar", aproximando os alunos da riqueza intelectual produzida historicamente. Nesse sentido, a atuação do professor na escola pública deve ser comprometida com este objetivo, com a transmissão dos conhecimentos científicos $(2008$, p. 20).

A construção coletiva de um currículo, para aqueles que acreditam e almejam a melhoria da qualidade de ensino, entretanto, foi apenas o primeiro passo em direção a um novo currículo. Afinal, não se realiza por si só, há necessidade de engajamento coletivo por parte dos professores, no intuito de organizar grupos, discutir, debater, estudar e compreender sua proposta pedagógica, condição para sua implementação.

\section{A COMPREENSÃO DOS DOCENTES DA REDE ACERCA DA PEDAGOGIA HISTÓRICO-CRÍTICA E SUA EFETIVAÇÃO NA SALA DE AULA}

A discussão que segue encontra-se amparada na pesquisa realizada no mês de fevereiro de 2019, com dez professores da Rede Municipal de Cascavel, 
que atuam nas turmas de pré-escola e do 10 ao 5 o ano em duas escolas diferentes. A mesma foi efetivada em forma de questionário tendo como o objetivo verificar a partir das respostas dos professores quais são as reais dificuldades encontradas no dia a dia em sala de aula para efetivação do currículo na perspectiva da Pedagogia Histórico-Crítica.

Sobre a compreensão efetiva da proposta pedagógica do Município de Cascavel, afirmam que, apesar de sua complexidade, os professores compreendem, traz reflexões sobre a concepção de homem e de sociedade. No entanto, percebe-se algumas contradições quando solicitado para citar até mesmo aspectos simples referentes a ela, como por exemplo, os autores que fundamentam a PHC. Dentre outros, são citados Paulo Freire e Vasconcellos, cujas perspectivas pedagógicas não condizem com essa teoria pedagógica. Isso demonstra que falta até mesmo conhecimentos básicos. Por isso, como nos diz Eduardo Galeano, "o barco não anda porque não tem água".

Consequentemente, é preciso ter conhecimento e clareza dos fundamentos que sustentam a Pedagogia Histórico-Crítica, a base teórica que proporciona uma maneira específica de compreender e transformar a prática pedagógica, a fim de possa superar a fragmentação, o esvaziamento do conhecimento em sala de aula e o ecletismo. De acordo com Saviani (2013, p. 421- 422)

[...] pode-se considerar que a pedagogia histórico-crítica é tributária da concepção dialética, especificamente na versão do materialismo histórico, tendo fortes afinidades, no que se refere às suas bases psicológicas, com a psicologia histórico-cultural desenvolvida pela escola de vigotski. a educação é entendida como o ato de produzir, direta e intencionalmente, em cada indivíduo singular, a humanidade que é produzida histórica e coletivamente pelo conjunto dos homens.

Ademais, ao serem solicitados que falassem sobre os desafios de se trabalhar na perspectiva da Pedagogia Histórico-Crítica, afirmaram que o grande desafio é formar cidadãos críticos e pensantes, proporcionar uma formação humanizadora e transformadora, em um mundo em que predomina a internet, em que as aulas são tradicionais, não atrativas aos alunos e falta articulação entre teoria e prática.

Por isso, é preciso estar atentos, pois, necessitamos de uma educação para além da escola (ORSO, 2011), em que os alunos aprendam a ler o mundo e compreendam a sociedade, afinal, se não forem capazes de transformar a realidade em que vivem, para que lhes serve o conhecimento?

Sem dúvida, o professor precisa buscar rumos diferentes no processo pedagógico. Num primeiro momento compreender que é parte da classe 
trabalhadora, ter consciência da sociedade em que está imerso, compreender o real papel da escola, desarticular-se da ideologia burguesa e promover ações em torno dos interesses dos trabalhadores, garantindo a eles o acesso ao saber elaborado de qualidade, elevando o nível de conhecimento, passando do senso comum para o conhecimento científico.

Desta forma, o professor não estará apenas cumprindo um mero trabalho, mas transformando-o em conhecimento vivo, possibilitando que os alunos de fato se apropriem, formando cidadãos que sejam capazes de agir, opinar, garantindo-lhes aquilo que é um direito que Ihes foi negado há muito tempo.

Nesse sentido, Orso (2017, p. 155) destaca que:

[...] ser materialista significa trabalhar com a materialidade, com as contradições e a realidade histórica em sua totalidade; significa não esquecer que a sociedade está fundada na propriedade privada, que é composta por classes e que assume determinada configuração em cada momento; significa não esquecer a qual classe se pertence e, muito menos, que se trata de luta e não de um clube de amigos. Consequentemente, quando se luta, não se pode lutar de qualquer jeito, sem plano, sem táticas, sem estratégia. Há que se planejar.

$\mathrm{Na}$ pergunta sobre a formação acadêmica, dos professores entrevistados, grande parte deles responderam que não tiveram aprofundamento teórico na perspectiva da PHC, que o que aprenderam foi nos cursos de formação continuada e na prática. Dizem que alguns professores não têm interesse de aprofundar seus conhecimentos na perspectiva de uma "práxis pedagógica" transformadora, conforme assevera Dermeval Saviani (2010, p. 233):

[...] uma formação ampla e aprofundada, centrada nos fundamentos da educação a partir dos quais seriam estudados os aspectos pedagógicos, didáticos, curriculares e organizacionais das escolas tendo em vista a distribuição, no espaço e tempo destinados ao trabalho pedagógico, dos ingredientes culturais necessários à formação das novas gerações. É claro, pois, que esse tipo de formação só poderá dar-se em cursos de longa duração.

Devemos ter em vista que, muitas vezes, o professor tem uma formação inicial precária, em cursos de curta duração, com a simplificação e minimização dos currículos. Por isso, recai sobre a escola uma grande responsabilidade no que se refere a superar esse déficit de formação inicial e 
buscar soluções efetivas, que permitam aos educadores atualização constante e consciência pedagógica, apesar de todas as dificuldades em sua formação.

Em relação à formação continuada proposta pela SEMED (Secretaria Municipal de Educação de Cascavel) a grande maioria dos professores respondeu que há preocupação no fornecimento de subsídios teóricos a eles. Todavia, alguns elencaram que precisam de mais formação para auxiliá-los na prática docente.

No entanto, observa-se que muitos profissionais apresentam dificuldades de compreender a proposta por falta de leitura, não conseguindo assimilar a teoria proporcionada nas formações. Consequentemente, também cabe a responsabilidade dos próprios professores buscarem conhecimentos por conta própria e assumam o compromisso com a efetivação da proposta em sua prática pedagógica.

Todavia, conforme Gasparin (2012), um dos pontos críticos da implantação do diferente processo de ensino e aprendizagem é a falta de suporte para os professores. Além de não ter materiais de apoio, muitos professores nem sempre têm tempo disponível para elaborar os planos para os conteúdos dentro da nova perspectiva, o que enseja o desânimo e o retorno ao velho caminho.

Trabalhar na perspectiva da Pedagogia Histórico-Crítica, como mencionamos acima com Orso, pressupõe afirmar que não existe uma fórmula pronta e acabada que pode ser aplicada a cada escola, trata-se de trabalhar com a materialidade e, consequentemente, revolucionar a realidade concreta de cada momento.

Com relação ao planejamento, a grande maioria dos professores afirma que dominam o método materialista histórico dialético, no entanto, destacam que a maior dificuldade está nos encaminhamentos relativos aos conteúdos, muitos não levam em consideração a contextualização do assunto, não delegam ao aluno um papel ativo durante a sua exposição e, com isso, comprometem a construção de um conhecimento mais elaborado. A pesquisa também mostrou que alguns professores não levam em consideração a proposta, são resistentes, procuram receitas, aulas prontas, muitas delas, infelizmente ainda baseadas em conteúdos tradicionais e em datas comemorativas.

Segundo Marsiglia e Batista (2012, p. 61):

A opção pelo método materialista histórico-dialético na elaboração do Currículo teve como finalidade constituir uma unidade de direção ao trabalho pedagógico desenvolvido na Rede e, dessa maneira, cooperar 
para que a ação docente seja direcionada de forma intencional e coerente.

Contudo, diferente disso, por vezes, muitos professores, esperam por um receituário de como ensinar, negando, assim, o método que fundamenta a proposta.

Por isso, ressaltamos a importância da questão metodológica. Ao planejar, portanto, cabe ao professor compreender como se dá o processo de ensino-aprendizagem, possibilitando o desenvolvimento do educando de forma intencional e planejada.

Conforme Marsiglia e Batista (2012, p. 62), o método:

[...] também se justifica por expressar o projeto de educação, sociedade e homem que os profissionais da educação da Rede apontaram em seus estudos e debates. Um projeto que compreende o desenvolvimento histórico dos homens a partir de um processo conflituoso, impulsionado pela luta de classes, num cenário amplamente marcado pela contradição entre o desenvolvimento das forças produtivas e as relações sociais de produção.

A prática pedagógica da Rede Municipal de Cascavel se propõe a ser unitária e coerente, articulada à pedagogia histórico-crítica. Para tanto, fundamenta-se em uma teoria filosófico-pedagógica que dá conta de transmitir os conhecimentos de forma adequada aos alunos, que busca superar a fragmentação dos mesmos e objetiva a emancipação.

Para Malanchen, Matos e Pagnoncelli (2016, p. 61):

A opção pelo método materialista histórico-dialético na elaboração do Currículo teve como finalidade constituir uma unidade de direção ao trabalho pedagógico desenvolvido na Rede e, dessa maneira cooperar para que a ação docente seja direcionada de forma intencional e coerente.

Assim, cabe todo o empenho do professor para que, ao ensinar os conteúdos aos alunos, façam-no da melhor forma, não esperando uma receita pronta (metodologia), levando em consideração que o trabalho do professor é teórico/prático.

Orso nos alerta que:

[...] é necessário superar a noção de educação como um trabalho desinteressado, como se os conteúdos fossem neutros, indiferentes e inoperantes. É preciso transformá-los em conhecimentos vivos, "trazer o 
mundo para dentro da escola" e fazer com que, por meio do ensino e da aprendizagem, os alunos se apropriem dele concretamente. (2017, p. 162-163).

Nessa perspectiva, Saviani (2012) propõe os cinco passos do método materialista histórico-dialético: a prática social inicial, a problematização, a instrumentalização, a catarse e a prática social final, articulados entre si. Ou seja, não devem ser compreendidos como momentos estanques, como uma sequência de passos e sim na totalidade de suas relações, contemplando a realidade existente, concreta, contextualizada em todas as áreas do conhecimento humano, articulando a prática com a teoria, superando o senso comum, atingindo a consciência filosófica. Segundo o autor:

[...] daí decorre um método pedagógico que parte da prática social em que professor e aluno se encontram igualmente inseridos, ocupando, porém, posições distintas, condição para que travem uma relação fecunda na compreensão e no encaminhamento da solução dos problemas postos pela prática social. Aos momentos intermediários do método cabe identificar as questões suscitadas pela prática social (problematização), dispor os instrumentos teóricos e práticos para a sua compreensão e solução (instrumentalização) e viabilizar sua incorporação como elementos integrantes da própria vida dos alunos (catarse). (SAVIANI, 2013, p. 422).

Portanto, para que o trabalho em sala de aula seja de qualidade, precisa-se ter domínio teórico, pois, permite a reflexão sobre sua prática, para que haja a verdadeira práxis pedagógica, precisa-se da indissociabilidade entre teoria e prática, ou seja, da prática mediada pela teoria, uma ação pedagógica comprometida com a qualidade da aprendizagem e com a emancipação humana. Muitas vezes, a aprendizagem não se efetiva porque a instrumentalização não é adequada e suficiente.

Os professores relatam que deveria ter mais grupos de estudos com discussões a respeito da proposta com a participação ativa dos mesmos. No entanto, contraditoriamente, alguns também sugerem palestras motivacionais que despertem o interesse dos professores, além de debates sobre a importância e o reconhecimento desses profissionais, pois, muitos estão desmotivados, tendo em vista que a sociedade não os reconhece como fundamentais na construção e transformação social, um reconhecimento que vai além da remuneração, relacionada à autoestima ou até mesmo à avaliação subjetiva, sobre o que o faz de si e do seu papel. 
Porém, Saviani salienta que, a despeito das dificuldades existentes na implementação da PHC nas escolas:

[...] cabe continuar batalhando, divulgando a proposta e buscando formas de articulá-la com a prática dos professores nas escolas, sabendo, porém que ela desempenha um papel de resistência. Sua função é manter os educadores mobilizados na busca de novas perspectivas para a educação em nosso país, mostrando que é possível uma educação diferente, mas com a clareza de que ela faz parte de um processo mais amplo e que só poderá ser implantada plenamente quando as transformações no âmbito da própria sociedade se verificarem. (2011, p.119).

É preciso lutar sim pela educação, mas também pela transformação da sociedade, não apenas para transformar a sociedade, nem somente pela educação, pois, educação e sociedade são indissociáveis. Assim, como afirma Orso (2008, p. 62), "ou nos organizamos e lutamos pela transformação da sociedade ou então não teremos uma educação de nova modalidade nem construiremos um homem novo".

É preciso, portanto, partir da prática social, trazer o mundo real à sala de aula e, por meio do trabalho pedagógico, possibilitar o acesso aos conhecimentos mais desenvolvidos, a compreensão do mundo e de si mesmos e, consequentemente, a luta pela transformação e emancipação humana. A transmissão do conhecimento sistematizado, transformado em saber escolar, é um processo que deve ser organizado e planejado. Neste sentido é importante destacarmos a dissertação de Leonete Dalla Vecchia Mazaro (2018), intitulada 'A Construção do Currículo para Rede Pública Municipal de Ensino de Cascavel (2005-2015)', em que faz uma análise documental e bibliográfica de documentos, decretos, ofícios, editais e orientações emitidos pela SEMED de Cascavel entre os anos de 2005 a 2015. De acordo com sua pesquisa, afirma que os professores da rede ainda demonstram insegurança, desconhecimento e dificuldades tanto em compreender como e assumir e incorporar essa teoria.

Nesta perspectiva Orso (2016, p. 107-108), aponta algumas condições fundamentais para que os educadores possam trabalhar na perspectiva da Pedagogia Histórico-Crítica, tais como: a necessidade do domínio dos conteúdos, domínio da teoria da PHC, conhecimento do método materialista histórico-dialético, conhecimento acerca do funcionamento da sociedade, construção de um projeto de educação para outro tipo de sociedade e compromisso com a perspectiva revolucionária.

Ou seja, precisamos conhecer, pesquisar, lutar e fazer uma educação mais democrática, crítica e transformadora, com uma prática coerente e 
unitária, que compreenda de forma adequada e efetivamente a realidade, buscando transformá-la. Uma educação em defesa da escola pública, gratuita de qualidade para a classe trabalhadora.

\section{CONSIDERAÇÕES FINAIS}

Diante do exposto, conclui-se que, no Estado do Paraná, a Pedagogia Histórico-Crítica permaneceu mais no discurso, enquanto que no Currículo Municipal de Cascavel se avança em fundamentos, cujas propostas visam questionar as contradições do processo educativo e a construção do ser social. Contudo, para sua efetivação na prática pressupõe um processo coletivo e continuado, há que se superar muitos obstáculos, como a falta de conhecimento sobre a concepção pedagógica e política, além da sistematização no planejamento.

A escola está inserida em uma sociedade capitalista, e o currículo de Cascavel pretende trabalhar numa perspectiva de superar esse modo de produção com sua ideologia dominante e implementar uma educação comprometida com o pleno desenvolvimento humano. Está em nossas ações, a possibilidade de construir uma prática na contramão do capital.

As dificuldades que os professores têm de trabalhar nessa perspectiva, deve-se, em parte, a reprodução de ações dentro do modo de produção, afinal, ninguém está descolado. Se não tivermos uma formação comprometida, a fim de identificar na prática profissional a possibilidade de fazer com que nossos alunos pensem, questionem, sejam críticos, reflitam, sejam ativos no processo ensino-aprendizagem e rompam com o que está posto.

Nossa tarefa, vai além da formação, no dia a dia, discutindo temas importantes, desconstruindo valores hegemônicos. Precisamos estar atentos para garantir uma educação que supere as desigualdades e não reforce a situação existente.

Além disso, é preciso lutar por mais investimentos, pensar na educação com máxima prioridade, ampliando recursos, melhorando a infraestrutura e as condições de trabalho.

A luta deve ser de todos os profissionais da educação, não apenas pela permanência do Currículo como norteador das ações pedagógicas, mas, também, pela real efetivação em sala de aula. Afinal, se não formos capazes de compreender e mudar a realidade sócio educacional, reproduzimos o status quo, ou seja, nossa própria condição de trabalhadores. Portanto, todos à luta por uma nova educação e uma nova sociedade, justa, igualitária e humana. 


\section{REFERÊNCIAS}

ABRANTES, Angelo Antonio. Como ensinar? O método da Pedagogia HistóricoCrítica e a aula como unidade concreta de relações sociais. In: PASQUALINI, Juliana Campregher; TEIXEIRA, Lucas André; AGUDO, Marcela de Moraes. Pedagogia Histórico-Critica: legado e perspectivas. Uberlândia: Navegando Publicações, 2018.

BASSO, Jaqueline Daniela; NETO, José Leite dos Santos; BEZERRA, Maria Cristina dos Santos. Pedagogia histórico-crítica e educação no campo: história, desafios e perspectivas atuais. São Carlos: Pedro \&João Editores e Navegando, 2016.

CASCAVEL (PR). Secretaria Municipal de Educação. Currículo para a Rede Pública Municipal de Cascavel: volume II: Ensino Fundamental - anos iniciais: 2008.

GASPARIN, João Luiz. Uma didática para a pedagogia histórico-crítica. Campinas, SP: Autores Associados, 2012.

MARSIGLIA, Ana Carolina Galvão. A prática pedagógica histórico-crítica na educação infantil e no ensino fundamental. Campinas: SP: Autores Associados, 2011.

MARSIGLIA, Ana Carolina Galvão.; BATISTA, Eraldo Leme. Pedagogia Histórico Crítica: desafios e perspectivas para uma educação transformadora. Campinas: SP: Autores Associados, 2012.

MAZARO, Leonete Dalla Vechia. A construção e implementação do Currículo para a Rede Pública Municipal de Ensino de Cascavel (2005-2015). 2018. Dissertação (Mestrado em Educação). Universidade Estadual do Oeste do Paraná, 2018.

ORSO, Paulino José. Educação na sociedade de classes: possibilidades e limites. In: ORSO, P.J., GONÇALVES, S.R. e MATTOS, V. M. Educação e Lutas de Classes. São Paulo: Expressão Popular, 2008.

ORSO, Paulino José. Por uma educação para além do capital e por uma educação para além da escola. In: ORSO, P.J., GONÇALVES, S.R. e MATTOS, V. M. Educação, Estado e Contradições Sociais. São Paulo: Outras Expressões, 2011.

ORSO, Paulino José. Pedagogia histórico-crítica e educação no campo, História, desafios e perspectivas atuais. São Carlos: Pedro \& João Editores e Navegando, 2016. 
ORSO, Paulino José.; MALANCHEN, Julia; CASTANHA, André Paulo. 100 anos da revolução russa. Campinas, SP: Armazém do Ipê, 2017.

PAGNOCELLI, Cláudia; MALANCHEN, Julia; MATOS, Neide da Silveira Duarte. 0 trabalho Pedagógico nas disciplinas escolares - contribuições a partir dos fundamentos da pedagogia histórico-crítica. Campinas, SP: Armazém do Ipê, 2016.

SAVIANI, Dermeval. Educação em diálogo. Campinas, SP: Autores Associados, 2011.

SAVIANI, Dermeval. Escola e democracia. 42 ed. Campinas, SP: Autores Associados, 2012.

SAVIANI, Dermeval. História das ideias pedagógicas no Brasil. 4ed. Campinas, SP: Autores Associados, 2013.

SAVIANI, Dermeval. Interlocuções pedagógicas: conversa com Paulo Freire e Adriano Nogueira e 30 entrevistas sobre Educação. Campinas, SP: Autores Associados, 2010. 